\title{
Article
}

\section{Assessment of Eating Habits and Perceived Benefits of Physical Activity and Body Attractiveness among Adolescents from Northeastern Romania}

\author{
Dana-Teodora Anton-Păduraru ${ }^{1}$ (D), Ioan Gotcă ${ }^{2, *}$, Veronica Mocanu ${ }^{2, *}$ (D), Veronica Popescu ${ }^{3}$, \\ Maria-Liliana Iliescu ${ }^{4}$, Egidia-Gabriela Miftode ${ }^{5}$ and Vasile-Lucian Boiculese ${ }^{4}$ \\ 1 Department of Mother and Child Medicine, “Grigore T. Popa” University of Medicine and Pharmacy, 16, \\ Universitatii Street, 700115 Iasi, Romania; dana.anton@umfiasi.ro \\ 2 Department of Morpho-Functional Sciences II, “Grigore T. Popa” University of Medicine and Pharmacy, 16, \\ Universitatii Street, 700115 Iasi, Romania \\ 3 Faculty of Physical Education and Sport, "Alexandru Ioan Cuza" University, 700554 Iași, Romania; \\ veronica.popescu@uaic.ro \\ 4 Department of Preventive Medicine and Interdisciplinarity, "Grigore T. Popa" University of Medicine \\ and Pharmacy, 16, Universitatii Street, 700115 Iasi, Romania; maria.iliescu@umfiasi.ro (M.-L.I.); \\ vasile.boiculese@umfiasi.ro (V.-L.B.) \\ 5 Department of Medical Sciences II, “Grigore T. Popa” University of Medicine and Pharmacy, 16, \\ Universitatii Street, 700115 Iasi, Romania; egidia.miftode@umfiasi.ro \\ * Correspondence: ioan.gotca@umfiasi.ro (I.G.); veronica.mocanu@umfiasi.ro (V.M.)
}

\section{check for} updates

Citation: Anton-Păduraru, D.-T; Gotcă, I.; Mocanu, V.; Popescu, V.; Iliescu, M.-L.; Miftode, E.-G.; Boiculese, V.-L. Assessment of Eating Habits and Perceived Benefits of Physical Activity and Body Attractiveness among Adolescents from Northeastern Romania. Appl. Sci. 2021, 11, 11042. https://doi.org/ 10.3390/app112211042

Academic Editor: Wojciech Kolanowski

Received: 28 September 2021

Accepted: 18 November 2021

Published: 22 November 2021

Publisher's Note: MDPI stays neutral with regard to jurisdictional claims in published maps and institutional affiliations.

Copyright: (c) 2021 by the authors. Licensee MDPI, Basel, Switzerland. This article is an open access article distributed under the terms and conditions of the Creative Commons Attribution (CC BY) license (https:/ / creativecommons.org/licenses/by/ $4.0 /)$.
Abstract: The purpose of this paper was to present the results of the evaluation of 1320 adolescents from 4 high schools in Iaşi, Romania regarding their eating habits and perceived benefits of physical activity and body attractiveness after they completed an anonymous questionnaire. The data analysis was performed using IBM SPSS version 18. The analysis of the nutritional status showed that over $70 \%$ of adolescents were of a normal weight. Most of them (63.56\%) consumed 3-4 meals/day, with breakfast being the most skipped meal $(60.53 \%)$. Compared with the boys, the girls consumed fewer whole grains, dairy products, and meat, but the girls consumed fruits and vegetables in approximately the same percentage. The adolescents studied consumed more fruits than vegetables, but the servings of fruits and vegetables consumed were not sufficient in the diets of many adolescents (39.31\%). Among the adolescents, $5.68 \%$ consumed at least 2 alcoholic drinks daily, and $37.87 \%$ consumed caffeine products one or more times per week. Among the boys, 95.20\% practiced regular physical activity, and $97.20 \%$ of the girls considered that the right nutrition plays a role in the prevention of obesity. The study of the self-perception profile showed that $89.8 \%$ of boys and $79.5 \%$ of girls considered that they had attractive bodies. According to the BMI, $86.7 \%$ of normal-weight adolescents and $84.8 \%$ of underweight adolescents considered themselves as having attractive bodies, while this was only considered by $73.5 \%$ of overweight and $56.7 \%$ of obese adolescents. It is necessary to introduce nutritional education in schools for the improvement of eating habits in children and adolescents. More studies are needed to appreciate the social behaviors (e.g., food intake, physical activity, and recreation time) and then develop interventions and national health programs to promote a healthy lifestyle, particularly healthy eating habits.

Keywords: adolescent; eating habits; perceived benefits of physical activity; perceived body attractiveness

\section{Introduction}

Adolescence, a critical period and a bridge between childhood and adulthood, is the most important and sensitive period in life. It is also a period of curiosity in which adolescents can engage in different risky activities (e.g., alcohol consumption, smoking, drug abuse, and unprotected sex). Adolescence is also a period of transition in which dietary patterns are built [1]. 
During adolescence, children try to assume responsibility for their eating habits, health attitude, and behavior, with adequate nutrition and physical activity being important factors that influence their health and quality of life [2]. The eating habits acquired during adolescence will persist into adulthood. Healthy eating habits are fundamental for growth, development, and the prevention of diet-related diseases in the future [3]. Some barriers to healthy eating are represented by a lack of time, lack of concern about healthy eating recommendations, and low socioeconomic level, which determines the limited availability of healthy food [4]. It is recommended to have an adequate and well-balanced diet with a variety of foods that will provide macro-and micronutrients [5].

\section{Materials and Methods}

\subsection{Participants and Study Design}

This was a cross-sectional study, and it was performed with the participation of adolescents enrolled in four high schools located in Iasi in the northeastern region of Romania. The selected schools included students from similar socioeconomic groups. The study sample included 1320 adolescents 14-18 years old, and written assent from the adolescents and written informed consent from their legal guardians were obtained. Data collection was performed via a face-to-face interview based on a structured, pre-tested questionnaire between January 2016 and December 2018. The participants completed the questionnaire anonymously in their classrooms at school under the guidance of the interviewers and the teachers. The information was obtained via an administered questionnaire which was divided into three sections: (1) the food frequency questionnaire (the short diet quality screener); (2) the Revised Physical Self-Perception Profile; and (3) physical activity.

The short diet quality screener (sDQS) was used to estimate the overall diet quality [6]. In this study, the participants were asked to report their habitual intake of (1) cereals; (2) vegetables; (3) fruit; (4) dairy products; (5) red meat, poultry, and fish; (6) meat substitutes; (7) sweetened foods; (8) alcoholic beverages; (9) drinks with caffeine; and (10) fast food. Standardized portion sizes were used to quantify the frequency of food intake. Food frequency consumption was arranged into three frequency response categories: "recommended daily consumption", "more than recommended daily consumption", and "less than recommended daily consumption" according to the Romanian nutrition guidelines [7].

The Revised Physical Self-Perception Profile (PSPP-R), a 6-item subscale of the body (perceived bodily attractiveness), was used to measure physical self-esteem [8]. The perceived benefits of physical activity were assessed using a scale consisting of 10 statements relating to its effects on health. The subjects' task was to assess their accuracy on a scale from 1 (definitely false) to 4 (definitely true).

The body mass index (BMI) was calculated in $\mathrm{kg} / \mathrm{m}^{2}$ and converted to BMI percentiles. Using the WHO percentiles method, the adolescents were divided into normal weight (5th-85th percentile), underweight (under the 5th percentile), overweight (85th-95th percentile), and obese groups (over the 95th percentile).

\subsection{Statistical Analysis}

The data were coded, entered into EXCEL ${ }^{\circledR}$, and then exported to the statistical application. The analyses were performed using IBM SPSS version 18. Statistically, values with a $p$-value of 0.05 were considered significant, thus setting up a level of confidence of $95 \%$. Most of the data were categorical, and thus we used for comparison the Chi-square test with the Fisher exact approximation when needed (the consistency condition of the Chi-square test was unfulfilled). Descriptive characteristics like the absolute and relative frequencies, means, and standard deviations were computed.

\section{Results}

The lot was formed by 1320 adolescents ( 639 boys and 681 girls), with $48.71 \%$ from rural areas and $51.29 \%$ from urban areas. Table 1 presents the analysis of the nutritional status according to the BMI. 
Table 1. Nutritional status of the lot studied.

\begin{tabular}{ccccc}
\hline & \multicolumn{3}{c}{ Nutritional Status } \\
\cline { 2 - 4 } & Underweight & Normal Weight & Overweight & Obese \\
\hline Boys & $78(12.21 \%)$ & $474(74.19 \%)$ & $71(11.11 \%)$ & $162.50 \%)$ \\
Girls & $183(26.87 \%)$ & $465(68.28 \%)$ & $27(3.96 \%)$ & $6(0.88 \%)$ \\
Total & $261(19.77 \%)$ & $939(71.14 \%)$ & $98(7.42 \%)$ & $22(1.67 \%)$ \\
\hline
\end{tabular}

Table 2 presents the relationship between the number of meals consumed daily and the BMI.

Table 2. The relationship between the number of meals consumed daily and the BMI.

\begin{tabular}{|c|c|c|c|c|c|c|}
\hline \multirow[b]{2}{*}{$\begin{array}{l}\text { The Number } \\
\text { of Meals/Day }\end{array}$} & \multicolumn{6}{|c|}{ BMI } \\
\hline & & Underweight & Normal Weight & Overweight & Obese & Total \\
\hline \multirow{3}{*}{$1-2$} & Boys & $15(9.60 \%)$ & $119(76.30 \%)$ & $19(12.20 \%)$ & $3(1.90 \%)$ & $156(100 \%)$ \\
\hline & Girls & $53(21.50 \%)$ & $180(73.20 \%)$ & $8(3.30 \%)$ & $5(2.00 \%)$ & $246(100 \%)$ \\
\hline & Total & $68(16.90 \%)$ & $299(74.40 \%)$ & $27(6.70 \%)$ & $8(2.00 \%)$ & $402(100 \%)$ \\
\hline \multirow{3}{*}{$3-4$} & Boys & $58(13.50 \%)$ & $315(73.10 \%)$ & $46(10.70 \%)$ & $12(2.80 \%)$ & $431(100 \%)$ \\
\hline & Girls & $119(29.20 \%)$ & $269(65.90 \%)$ & $19(4.70 \%)$ & $1(0.20 \%)$ & $408(100 \%)$ \\
\hline & Total & $177(21.10 \%)$ & $584(69.60 \%)$ & $65(7.70 \%)$ & $13(1.50 \%)$ & $839(100 \%)$ \\
\hline \multirow{3}{*}{$5-6$} & Boys & $5(10.60 \%)$ & $38(80.90 \%)$ & $4(8.50 \%)$ & $0(0.00 \%)$ & $47(100 \%)$ \\
\hline & Girls & $9(39.10 \%)$ & $14(60.90 \%)$ & $0(0.00 \%)$ & $0(0.00 \%)$ & $23(100 \%)$ \\
\hline & Total & $14(20.00 \%)$ & $52(74.30 \%)$ & $4(5.70 \%)$ & $0(0.00 \%)$ & $70(100 \%)$ \\
\hline \multirow{3}{*}{$7+$} & Boys & $0(0.00 \%)$ & $2(40.00 \%)$ & $2(40.00 \%)$ & $1(20.00 \%)$ & $5(100 \%)$ \\
\hline & Girls & $2(50.00 \%)$ & $2(50.00 \%)$ & $0(0.00 \%)$ & $0(0.00 \%)$ & $4(100 \%)$ \\
\hline & Total & $2(22.22 \%)$ & $4(44.40 \%)$ & $2(22.22 \%)$ & $1(11.11 \%)$ & $9(100 \%)$ \\
\hline \multirow{3}{*}{ Total } & Boys & $78(12.20 \%)$ & $474(35.90 \%)$ & $71(5.37 \%)$ & $16(1.21 \%)$ & $639(100 \%)$ \\
\hline & Girls & $183(26.87 \%)$ & $465(68.28 \%)$ & $27(3.96 \%)$ & $6(0.88 \%)$ & $681(100 \%)$ \\
\hline & Total & $261(19.77 \%)$ & $939(71.13 \%)$ & $98(7.42 \%)$ & $22(1.66 \%)$ & $1320(100 \%)$ \\
\hline
\end{tabular}

In our study, 402 adolescents, of which 156 were boys (24.41\%) and $246(36.12 \%)$ were girls, skipped breakfast, but all the 1320 adolescents consumed dinner. Another part of the adolescents skipped lunch because they needed to go to school. In addition, 518 adolescents $(39.24 \%)$ consumed at least one snack per day, with a range from 1 to 4 .

Table 3 presents the daily consumption of different types of foods.

Table 3. Food group intake in the lot studied.

\begin{tabular}{|c|c|c|c|c|c|c|c|c|c|c|}
\hline \multirow{3}{*}{$\begin{array}{c}\text { Number of } \\
\text { Servings }\end{array}$} & \multicolumn{10}{|c|}{ Type of Foods } \\
\hline & \multicolumn{2}{|c|}{ Whole Grains } & \multicolumn{2}{|c|}{ Vegetables } & \multicolumn{2}{|c|}{ Fruits } & \multicolumn{2}{|c|}{ Dairy } & \multicolumn{2}{|c|}{ Meat } \\
\hline & $6-11$ & $\leq 5$ & $3-5$ & $\leq 2$ & $2-4$ & $\leq 1$ & $2-3$ & $\leq 1$ & $2-3$ & $\leq 1$ \\
\hline Boys & $\begin{array}{c}46 \\
(7.19 \%)\end{array}$ & $\begin{array}{c}593 \\
(92.80 \%)\end{array}$ & $\begin{array}{c}176 \\
(27.54 \%)\end{array}$ & $\begin{array}{c}463 \\
(72.50 \%)\end{array}$ & $\begin{array}{c}393 \\
(61.5 \%)\end{array}$ & $\begin{array}{c}246 \\
(38.49 \%)\end{array}$ & $\begin{array}{c}194 \\
(30.35 \%)\end{array}$ & $\begin{array}{c}445 \\
(69.64 \%)\end{array}$ & $\begin{array}{c}491 \\
(76.80 \%)\end{array}$ & $\begin{array}{c}148 * \\
(23.16 \%)\end{array}$ \\
\hline Girls & $\begin{array}{c}25 \\
(3.67 \%)\end{array}$ & $\begin{array}{c}656 \\
(96.30 \%)\end{array}$ & $\begin{array}{c}170 \\
(24.96 \%)\end{array}$ & $\begin{array}{c}511 \\
(75.00 \%)\end{array}$ & $\begin{array}{c}408 \\
(59.91 \%)\end{array}$ & $\begin{array}{c}273 \\
(40.08 \%)\end{array}$ & $\begin{array}{c}125 \\
(18.35 \%)\end{array}$ & $\begin{array}{c}556 \\
(81.64 \%)\end{array}$ & $\begin{array}{c}398 \\
(58.40 \%)\end{array}$ & $\begin{array}{c}283 \\
(41.55 \%)\end{array}$ \\
\hline
\end{tabular}

Pearson's Chi-squared test was used to compare categorical variables. ${ }^{*} p$-value significantly different between groups $(p<0.05)$.

Of the $77.80 \%$ of adolescents who consumed less than three servings/day of whole grains, only $4.60 \%$ consumed more than six servings/day of refined cereals. In contrast, $47.90 \%$ of adolescents who consumed at least six servings of whole grains/day also consumed $4-6$ servings/day of refined cereals. There was no statistically significant difference 
regarding the relationship between the BMI and the number of daily servings of refined cereals consumed $(p=0.105)$.

The fruit consumption was approximately equal for the two sexes; 519 (39.31\%) adolescents consumed less than 2 servings of fruits per day, but about one third of them $(32.90 \%)$ consumed more than 3 servings/day of sweets. In addition, a close percentage of those who consumed more than 2 servings of fruits/day (37\%) consumed over 3 servings of sweets daily, with the difference not being statistically significant $(p=0.215)$.

In our study, $26.20 \%$ of the adolescents (346) consumed at least 3 servings of vegetables/day, and $16.00 \%$ of adolescents (211) consumed at least 3 servings of high-fat foods daily (e.g., fries, snacks, and chips). We did not observe an inversely proportional relationship between fruit consumption and fatty foods $(p=0.066)$. The study of the relationship between the daily consumption of vegetables and that of high-fat foods revealed that 305 of those with adequate consumption of vegetables (minimum: 3 servings/day) consumed less than 2 servings/day of fatty foods.

Analysis of the consumption of milk products showed that only 319 adolescents ( $24.16 \%)$ consumed more than 2 servings daily; 129 adolescents $(9.77 \%)$ did not consume milk or rarely consumed it, with no significant differences between the boys and girls. Of the 467 adolescents who consumed sweets in large quantities (over 3 servings/day), $40(8.56 \%)$ consumed milk in very small quantities or not at all.

Among the adolescents, 187 consumed more than 3 servings of meat per day, with the number of boys being 2.81 times higher than that for girls (138 versus 49 ). Only 87 teenagers $(6.59 \%)$, of which 57 were girls, consumed meat rarely or at all, and $24.50 \%$ of the girls who consumed more than 3 servings of meat per day also consumed foods high in fat. Meanwhile, $90.70 \%$ of the boys who consumed meat only a few times per week consumed even less fat (under 3 servings/day). Analysis of the diets of adolescents who consumed meat only a few times per week showed that they did not consume more protein from another group (over three servings per day). In contrast, $86.60 \%$ of those who consumed high amounts of meat also consumed high amounts of other high-protein foods. The study of the relationship between meat consumption and sweets revealed statistically significant differences in the fact that both girls and boys who consumed more meat consumed more sweets ( $p=0.00) ; 48.70 \%$ of adolescents who consumed more than 3 daily portions of meat and meat products consumed more than 3 servings of sweets per day.

Of all participants, 75 adolescents (5.68\%) consumed at least 2 alcoholic drinks daily. Although the difference observed was small $\left(1 \mathrm{~kg} / \mathrm{m}^{2}\right)$, we found that the BMI increased with increasing alcohol consumption $(p=0.005)$. In addition, 500 of the adolescents surveyed (37.87\%) in approximately equal proportions of girls and boys consumed caffeine products 1 or more times per week. Of these adolescents who consumed caffeine, $94.30 \%$ consumed a maximum of 1 alcoholic drink per day, and only $5.70 \%$ consumed over 2 alcoholic drinks per day. In contrast, boys who consumed only green tea and decaffeinated products weekly showed a greater percentage $(35.90 \%)$ of those who consumed over 2 alcoholic drinks daily $(p=0.018)$. Additionally, $50.90 \%$ of those who consumed caffeine several times per week slept 7-8 h/night, which was almost the same as those who did not use caffeine $(53.80 \%)$. Only $4.70 \%$ of adolescents who frequently used caffeine had a short sleep duration of 3-4 h/night. There were no significantly lower BMI values for those who slept longer (7-8 h/night) compared with those who slept only 3-4 h/night or 5-6 h/night.

In our study, we established the upper percentile for the body attractiveness of the physical self-perception subscale (score $>21$ ) to indicate adolescents who perceived that they had attractive bodies. The study of the profile of physical self-perception revealed that 556 boys $(89.8 \%)$ and 529 girls $(79.5 \%)$ considered that they had attractive bodies. Of these, 133 boys and 102 girls participated with pleasure in physical education and sports. Over $75 \%$ of the subjects who considered that they had attractive bodies $(76.50 \%$ boys and $72.60 \%$ girls) participated in sports activities during their leisure. These boys had a better perception of how they looked physically $(p=0.000)$. On the other hand, there was a tendency for those who carry out more physical activity to perceive their body as 
more attractive $(71.40 \%$ of boys and $69.40 \%$ of girls). According to the BMI, $84.8 \%$ of the underweight group, $86.7 \%$ of the normal weight group, $73.5 \%$ of the overweight group, and $56.7 \%$ of the obesity group considered their bodies to be attractive.

In the study group, 904 adolescents $(68.50 \%)$ considered that a greater number of hours of physical education per week would be necessary. Among these subjects, 591 (44.77\%) liked to participate in individual sports activities and $633(47.95 \%)$ liked team sports activities. Additionally, $74.40 \%$ of the boys and $49.80 \%$ of the girls who practiced individual sports also participated in team sports $(p=0.000)$. Only 727 of the total adolescents $(55.07 \%)$ participated daily with pleasure in sports activities, while 35 of the boys $(5.47 \%)$ and 70 of the girls $(10.27 \%)$ did not participate in physical education classes at all.

Of those who practiced regular physical activity, $95.20 \%$ of the boys and $97.20 \%$ of the girls considered that the right nutrition played a role in the prevention of obesity $(p=0.000)$.

Meanwhile, 273 of the 433 boys and 192 out of 294 girls ( $p=0.025$ ) who took part in daily physical activities consumed fruits in quantities greater than 2 servings/day ( $p=0.311$ ), while $66.50 \%$ of the boys who did not take pleasure in sports activities consumed less than 2 servings of milk per day, as did $82.90 \%$ of the girls. Some of them $(24.30 \%$ boys and $6.50 \%$ girls) did not consume any meat in the recommended quantity.

\section{Discussion}

Adolescence is a critical period characterized by changes in body composition, morphological changes (e.g., increase in lean mass in boys and body fat in girls), hormonal changes, increased rhythm of growth, and a tendency toward independence and preoccupation with one's self-image [9].

The analysis of the nutritional status of the studied group showed that over $70 \%$ of adolescents were of normal weights (35.9\% of boys and $35.22 \%$ of girls), $19.76 \%$ were underweight, and the rest $(9.07 \%)$ were overweight or obese. The majority of the boys and girls had adequate weights. Comparatively, the results of other studies on adolescents from different parts of the world are mentioned in Table 4.

Table 4. Nutritional status of adolescents included in other studies.

\begin{tabular}{cccccc}
\hline & \multicolumn{3}{c}{ Nutritional Status } \\
\hline Study & $\begin{array}{c}\text { Number of } \\
\text { Adolescents }\end{array}$ & $\begin{array}{c}\text { Normal Weight } \\
\mathbf{( \% )}\end{array}$ & $\begin{array}{c}\text { Underweight } \\
\mathbf{( \% )}\end{array}$ & $\begin{array}{c}\text { Overweight } \\
\mathbf{( \% )}\end{array}$ & $\begin{array}{c}\text { Obese } \\
\mathbf{( \% )}\end{array}$ \\
\hline Mizia et al., 2011, Poland [10] & 307 & $74.55 \%$ & $9.40 \%$ & $13.75 \%$ & $2.30 \%$ \\
Gill et al., 2016, Islamabad [1] & 290 & $60.70 \%$ & $27.20 \%$ & $9.30 \%$ & $2.80 \%$ \\
Lestari et al., 2018, Indonesia [1] & 400 & $57.20 \%$ & 23.30 & $13.00 \%$ & $6.50 \%$ \\
Agofure et al., 2010, Nigeria [12] & 201 & $31.80 \%$ & $46.80 \%$ & $21.40 \%$ & \\
\hline
\end{tabular}

In contrast to the results of a study conducted on Spanish adolescents, in which $20 \%$ of the participants were overweight and obese [13], we found differences between the sexes in the number of underweight and overweight participants in the study; more girls were underweight (26.87\% versus $12.20 \%)$, but more boys were overweight $(11.11 \%$ versus $3.96 \%$ ). For a better assessment of the nutritional status of adolescents, we consider that it is necessary to determine not only the BMI but also the assessment of body fat composition.

Only 70 adolescents $(5.30 \%)$ of the studied group consumed 5-6 meals/day, with most (63.56\%) consuming 3-4 meals/day. The number of boys having 5-6 meals / day was double that of girls (47 versus 23). In the study of Castañeda-Sánchez et al., 52.20\% of the adolescents included had 3 meals per day, and only 13\% had more than 3 meals per day [14]. The results of the study by Gill et al. showed that $91.40 \%$ of the 290 adolescents from Islamabad consumed a maximum of 3 meals/day, $6.20 \%$ consumed 4 meals/day, and $2.40 \%$ of them had over 5 meals/day [1].

The analysis of the relationship between the number of meals/day and the BMI value revealed that only 3 adolescents who had over 7 meals/day were overweight or obese, 
while 27 adolescents consuming only 1-2 meals/day were overweight or obese. This could be explained by the fact that, due to the school program, they consumed the largest amount of food in the evening.

The risk factors for being overweight or obese are skipping meals, physical inactivity, regular consumption of fatty and sweet foods, and fast food [15]. The habit of skipping meals-a common phenomenon among adolescents-contributes to dietary inadequacy and increased body weight, as the foods commonly consumed and may even be replaced by unhealthy foods [16].

Breakfast provides $25 \%$ of the daily caloric intake. It is considered that the regular consumption of breakfast is associated with a lower BMI and a reduced risk of obesity. Breakfast is important as it provides energy, vitamins, and minerals. Regularly eating breakfast can reduce the consumption of snacks and energy-rich foods [17]. Meal skipping is common among adolescents, with breakfast being the most-skipped meal. The reasons why they do not have breakfast are the desire to sleep longer, the lack of time, and the start of the school program being at 7:00 a.m. For these reasons, they eat outside the home (e.g., vending machines, fast food restaurants, and food courts). Many of these types of foods are high in fat and low in nutrients and fibers. By contrast, the mostconsumed meal is dinner, which provides a larger proportion of calories and nutrients. Compared with the study of Stang and Story (2005) [18], where $28.00 \%$ of boys and 34.00\% of girls did not consume breakfast and $88.00 \%$ consumed at least one snack daily, in our study, the percentage of adolescents that did not consume breakfast was similar, but the percentage of those who consumed snacks was lower (39.24\% versus $88.00 \%$ ). Other studies concluded that in Albania, 24\% of adolescents skipped breakfast, only 52\% consumed breakfast in Austria, and in Brazil, 47\% of adolescents consumed breakfast [4,19,20]. In another Romanian study by Pantea et al., 36.30\% of adolescent girls skipped breakfast compared with $22.80 \%$ of Polish girls in the study by Kollataj et al., cited by Gill et al. [1,19]. By contrast, $79.30 \%$ of Turkish adolescents studied by Ozkan et al. skipped breakfast, a big percentage of adolescents that skipped breakfast being in Bahrain in the study by Musaiger et al. (62.80\% of girls and $37.20 \%$ of boys) $[20,21]$. In the study by Vizbaraite et al., $28.50 \%$ of the Lithuanian adolescents studied skipped breakfast (especially the girls), and for breakfast, the boys in particular ate chips, fried foods, and buns [2]. The study by Onyiriuka et al. revealed that $48 \%$ of the Nigerian adolescents studied skipped at least one meal, with breakfast being the most frequently skipped meal (46\%), followed by dinner $(22 \%)$, and the main reasons for skipping breakfast were a lack of time and appetite [3]. In 2016 , in a WHO study about adolescents' dietary habits, they mentioned that only $40 \%$ of boys and $36 \%$ of girls from Romania consumed breakfast compared with $86 \%$ of boys and $73 \%$ of girls from Portugal, $81 \%$ of boys and $71 \%$ of girls from Holland, $74 \%$ of boys and $66 \%$ of girls from Denmark [17].

An assessment of food and beverages is necessary for highlighting the association between diet and health [22]. Poor eating habits in adolescence, together with other lifestyle factors, can lead to the appearance of some diseases later (i.e., diet-related chronic diseases) [15]. It is known that correct nutrition is important in the prevention of some diseases (e.g., obesity, type 2 diabetes, anemia, cardiovascular diseases, cancers, endocrines disorders, and psychological diseases) $[9,23]$. The types of food consumed and their nutritional content influence the growth and development of children. The selection of food is influenced by different factors, but adolescents are the most vulnerable population when they have to make healthy choices [24]. Snacks provide a high amount of the total daily energy intake in adolescents [25].

In the HELENA study, the intake of meat, fats, and sweets was higher than recommended [10]. In our study, a high percentage of the adolescents studied consumed under the minimum number of servings per day recommended in the Food Guide Pyramid [26] (Table 3). Compared with the boys, the girls who were 14-18 years old consumed fewer whole grains, dairy products, and meat, but the girls consumed fruits and vegetables in 
approximately the same percentage. We remarked on the low consumption of whole grains for both sexes.

Compared with the study by Stang and Story [15], where only $5 \%$ of adolescent boys respected the recommendations for all food groups, in our study, $7.19 \%$ of boys respected these recommendations.

Proteins are a major nutrient needed for the growth and development of adolescents. One's diet must contain animal and vegetable proteins in equal proportions, in accordance with the health recommendations. However, 87 adolescents $(6.59 \%)$ who consumed meat rarely or at all consumed no proteins from other sources. The inadequate intake of milk and dairy products could be associated with an inadequate calcium intake. This could increase the risk for fractures in adolescents and for osteoporosis later $[9,10,22,23,25]$. In the study by Onyiriuka et al., only $19.10 \%$ of adolescent girls ate meat daily, and only $8.10 \%$ had milk and dairy [3]. Musaiger et al. observed that $37.10 \%$ of the 735 adolescents studied consumed milk daily, and $20 \%$ consumed meat daily [21]. Similar to the study by Drenowatz et al., boys reported more frequent consumption of meat [25].

Sweets consumption is very popular among adolescents, as are fast food products. Skipping one meal, more frequently breakfast, determines a high consumption of other foods like sweets [25]. Bazhan et al. found in their study on 400 adolescents that many of them consumed sweet foods (87\%) [27]. A high percentage (46.40\%) was also found in the study by Castañeda-Sánchez et al. [14].

The reduced consumption of fruits and vegetables also implies a lower supply of fibers with a role in the prevention of chronic degenerative diseases, cancer, and improvement of motility and the functions of the gastrointestinal system [23]. A study on Spanish adolescents' eating habits showed that in the majority of them, the ingestion of fruits and vegetables was less than recommended [13]. Similar data were provided by an Albanian study in which $72.5 \%$ of adolescents did not eat at least 2 servings of fruits and vegetables per day and by a Nigerian study in which only $15.20 \%$ of adolescent girls ate fruits and vegetables daily $[3,4]$. In Nordic countries, $38.10 \%$ of adolescents ate fruits rarely, and $26.90 \%$ only had them 1-3 times per week [28]. According to the questionnaire administered, the adolescents studied by us consumed more fruits than vegetables, but the serving of fruits and vegetables consumed was not sufficient in the diet of many adolescents (39.31\% compared with $22.90 \pm 10.30 \%$ in the study by Colic Baric et al. (2000)) [24]. In the same study, $3.20 \pm 1.90 \%$ of adolescents consumed alcohol daily, with the boys doing so more often than the girls [24]. One hundred five adolescents who participated in the "Cooking and Active Leisure" TAS program consumed at least one alcoholic beverage during the week [13]. Alcohol consumption is present among adolescents, with alcohol altering nutrient absorption and metabolism.

In our study, most adolescents $(77.00 \%)$ consumed a maximum of 3 servings of whole grains per day, while $36.60 \%$ consumed over 6 servings/day. No statistically significant differences were observed between adolescents who consumed at least 6 servings of whole grains per day and those who consumed between 1 and 5 servings/day. In addition, no differences were observed between those who consumed refined cereals in high quantities (over six servings/day) and those who consumed small quantities.

A higher percentage of underweight subjects was found in adolescents that practiced physical activity. Adolescents with low levels of physical activity are more predisposed to develop unhealthy eating habits [29]. Adolescents that practice low physical activity have shown high rates of consumption of sugar [13]. In Finnish adolescents, a decreasing trend in physical activity, especially in adolescent girls, was found [28].

The body image consists of perceptive and attitudinal (body dissatisfaction regarding weight and physical appearance) dimensions. In adolescents, body dissatisfaction is associated with weight and the percentage of body fat [29]. In our study, body dissatisfaction was found in approximately equal numbers in the 2 sexes: 197 boys $(30.82 \%)$ and 219 girls $(32.15 \%)$. The study of the self-perception profile showed that $86.7 \%$ of normal-weight and $84.8 \%$ of underweight adolescents considered that they had attractive bodies, while 
only $73.5 \%$ of overweight and $56.7 \%$ of obese adolescents thought so. Therefore, we can conclude that the obese adolescents had low self-esteem.

Taken all together, we consider that nutritional education is necessary for adolescents, with the goals being the following:

- The introduction and development of healthy eating behaviors;

- Creating a positive attitude about food;

- Development of healthy eating habits;

- Encouraging the acceptance of various foods;

- $\quad$ Understanding the relationship between food and health;

- Offering foods that contain adequate amounts of nutrients but are not excessive [30].

Strengths and limitations of the study. Among the strengths, we can enumerate the following: the large and representative sample of adolescents from four different high-schools (two technological, one educational, and one theoretical) participating in the study, and the multidisciplinary working team pediatrics, public health, endocrinologist, psychologist, physical education, and sports teachers. The limitations of the study could be represented by the fact that the data about dietary habits and physical activity were self-reported by the adolescents studied, but we think that the anonymous character of the questionnaire encouraged them to give honest responses. Another limitation is represented by the fact that the socioeconomic status was not considered in the analysis.

Relevance of the findings: implications for clinicians and policymakers. Taking into account that education is a protective factor [31], we organized educational activities such as didactic lectures followed by interactive sessions to clarify their lack of knowledge about nutrition and physical activities as well as their importance. We encouraged the adolescents to have dialogue with teachers, family doctors, and nutritionists. We implemented an educational intervention in the schools participating in this study, which was appreciated as being very useful by adolescents and teachers who participated in the nutrition education program. We hope that the adolescents included in the study will pass on the acquired knowledge to other teenagers, their brothers and sisters, and even their parents and relatives.

From the point of view of policymakers, we consider that two aspects must be solved. First, it is necessary to introduce into the school curriculum hours of nutritional education that provide correct and age-appropriate information for students. Secondly, in the medical care team, the presence of a nutritionist and a psychologist for counseling adolescents is necessary.

\section{Conclusions}

Maintaining an optimal level of physical activity and nutritional education are both important to reduce the risk of being overweight or obese. The regular consumption of breakfast contributes to the establishment of healthy dietary patterns. Skipping meals is associated with a low-quality diet, low consumption of fruits and vegetables, and high consumption of fats, sugar, sodium, and alcohol.

Author Contributions: Conceptualization, D.-T.A.-P. and V.M.; methodology, E.-G.M., I.G. and V.P.; investigation, D.-T.A.-P.; data curation, V.-L.B., M.-L.I. and E.-G.M.; writing-original draft preparation, D.-T.A.-P.; writing-review and editing, V.M. All authors have read and agreed to the published version of the manuscript.

Funding: This research received no external funding.

Institutional Review Board Statement: This study was conducted with the approval of County School Inspectorate of Iasi, Romania and after signing a collaboration agreement with the directors of the four high schools included in the study. This study was approved by the Research Ethics Committee of "Grigore T. Popa" University of Medicine and Pharmacy in Iaşi, Romania (No. 23512/29.10.2019). 
Informed Consent Statement: An informed consent form was signed by the school directors, parents, and students.

Acknowledgments: We thank the principals, teachers, and students who participated in the study.

Conflicts of Interest: The authors declare no conflict of interest.

\section{References}

1. Gill, F.N.; Majeed, A.; Qureshi, Z.; Khan, K.A.; Khan, M.A. An Assessment of Adolescent Eating Habits in Public Schools of Chak Shahzad, Islamabad. Int. J. Nutr. Food Sci. 2016, 5, 304-309. [CrossRef]

2. Vizbaraite, D.; Griciute, A.; Jankauskiene, R.; Pajaujienc, S. Evaluation of Nutrition Habits of Adolescents in the Aspect of Gender and Physical Activity. J. Sport Health Sci. 2011, 2, 52-58. [CrossRef]

3. Onyiriuka, A.; Ibeawuchi, A.; Onyiriuka, R. Assessment of eating habits among adolescent Nigerian urban secondary school girls. Sri Lanka J. Child Health 2013, 42, 20-26. [CrossRef]

4. Citozi, R.; Bozo, D.; Pano, G. An assessment of the perception of physical activity, eating habits, self-efficacy and the knowledge about healthy food in Albanian adolescents. J. Hum. Sport Exercise 2013, 8, S192-S203. [CrossRef]

5. Lago, R.R.; Ribeiro, T.H.T.; de Souza, M.N.C. Eating habits of adolescents: A literature review. Adolesc. Saude 2016, 13, 98-103.

6. Schroder, H.; Benitez Arciniega, A.; Soler, C.; Covas, M.I.; Baena-Diez, J.M.; Marrugat, J. Validity of two short screeners for diet quality in time-limited settings. Public Health Nutr. 2012, 15, 618-626. [CrossRef]

7. Graur, M. Romanian Guide to Healthy Eating; Editura Performantica: Iasi, Romania, 2006.

8. Lindwall, M.; Asci, H.; Hagger, M.S. Factorial validity and measurement invariance of the Revised Physical Self-Perception Profile (PSPP-R) in three countries. Psychol. Health Med. 2011, 16, 115-128. [CrossRef]

9. Amos, P.M.; Intiful, F.D.; Boateng, L. Factors that were found to influence Ghanaian adolescents' eating habits. SAGE Open 2012, 2, 1-6. [CrossRef]

10. Mizia, S.; Felinczak, A.; Wlodarek, D.; Syrkiewicz-Switala, M. Evaluation of Eating Habits and Their Impact on Health among Adolescents and Young Adults: A Cross-Sectional Study. Int. J. Environ. Res. Public Health 2021, 18, 3996. [CrossRef]

11. Lestari, S.; Fujiati, I.I.; Eyanoer, P.C.; Sari, D.K.; Panjaitan, S.A.A.; Nasution, N.H. Prevalence of Nutritional Status and Dietary Habits among Adolescent in Urban Area in Medan, North Sumatera, Indonesia. In Proceedings of the International Conference of Science, Technology, Engineering, Environmental and Ramification Researches, Medan, Indonesia, 30-31 August 2018.

12. Agofure, O.; Odjimogho, S.; Okandeji-Barry, O.; Moses, V. Dietary pattern and nutritional status of female adolescents in Amai Secondary School, Delta State, Nigeria. Pan. Afr. Med. J. 2021, 38, 32. [CrossRef]

13. Roura, E.; Mila-Villarroel, R.; Lucia Pareja, S.; Adot Caballero, A. Assessment of Eating Habits and Physical Activity among Spanish Adolescents. The "Cooking and Active Leisure" TAS Program. PLoS ONE 2016, 11, e0159962. [CrossRef] [PubMed]

14. Castañeda-Sánchez, O.; Rocha-Diaz, J.C.; Ramos-Aispuro, M.G. Evaluation of Eating Habits and Their Relationship with the Nutritional Status of Adolescents at Sonora, Mexico. Arch. Med. Fam. 2008, 10, 7-9.

15. Sarkar, M.; Manna, N.; Sinha, S.; Sarkar, S.; Pradhan, U. Eating habits and nutritional status among adolescent school girls: An experience from rural area of West Bengal. IOSR JDMS 2015, 14, 6-12.

16. Silva, F.A.; Candia, S.M.; Pequeno, M.S.; Sartorelli, D.S.; Mendes, L.L.; Oliveira, R.M.; Netto, M.P.; Candido, A.P. Daily meal frequency and associated variables in children and adolescents. J. Pediatr. (Rio J.) 2017, 93, 79-86. [CrossRef] [PubMed]

17. World Health Organization. Adolescents' Dietary Habits. Fact Sheet. Available online: https://www.euro.who.int/__data/ assets /pdf_file/0006/303477/HBSC-No.7_factsheet_Diet.pdf\%3Fua\%3D1 (accessed on 10 November 2021).

18. Stang, J.; Story, M. Understanding adolescent eating behaviors. In Guidelines for Adolescent Nutrition Services; Stang, J., Story, M., Eds.; University of Minnesota: Minneapolis, MN, USA, 2005; pp. 9-19. Available online: http://www.epi.umn.edu/let/pubs/ adol_book (accessed on 10 November 2021).

19. Drenowatz, C.; Greier, K.; Klein, P. Associations between eating habits and food intake in Austrian adolescents. Ann. Clin. Nutr. 2018, 2, 1010.

20. Rodrigues, P.R.M.; Luiz, R.R.; Monteiro, L.S.; Ferreira, M.G.; Goncalves-Silva, R.M.V.; Pereira, R.A. Adolescents' unhealthy eating habits are associated with meal skipping. Nutrition 2017, 42, 114-120. [CrossRef]

21. Pantea Stoian, A.; Andronache, L.; Hainaroșie, R.; Păduraru, D.; Badiu, C.; Arsene, A. Dietary habits and lifestyle in school-aged children from Bucharest, Romania. J. Mind Med. Sci. 2018, 5, 85-92. [CrossRef]

22. Őzkan, B.A.; Yeșilkay, B.; Yaldiz, N.; Pehliva, M. Factors affecting diet quality in adolescents. The effect of sociodemographic characteristics and meal consumption. Prog. Nutr. 2020, 22, e2020094.

23. Musaiger, A.O.; Bader, Z.; Al-Roomi, K.; D'Souza, R. Dietary and lifestyle habits amongst adolescents in Bahrain. Food Nutr. Res. 2011, 55. [CrossRef]

24. Perez-Rodrigo, C.; Artiach Escauriaza, B.; Artiach Escauriaza, J.; Polanco Allue, I. Dietary assessment in children and adolescents: Issues and recommendations. Nutr. Hosp. 2015, 31, 76-83.

25. Vereecken, C.A.; De Henauw, S.; Maes, L. Adolescents' food habits: Results of the Health Behaviour in School-aged Children survey. Br. J. Nutr. 2005, 94, 423-431. [CrossRef]

26. Colic Baric, I.; Kajfez, R.; Cvijetic, S. Dietary Hbaits and Nutritional Status of Adolescents. Food Technol. Biotechnol. 2000, $38,217-224$. 
27. USDA. Dietary Guidelines for Americans; U.S. Government Printing Office: Washington, DC, USA, 2010.

28. Bazhan, M.; Kalantari, N.; Houhiar-Rad, A.; Alavi-Majd, H.; Kalantari, S. Dietary habits and nutrient intake in adolescent girls living in Northern Iran. J. Paramed Sci. 2013, 4, 93-98.

29. Samuelson, G. Dietary habits and nutritional status in adolescents over Europe. An overview of current studies in the Nordic countries. Eur. J. Clin. Nutr. 2000, 54 (Suppl. S1), S21-S28. [CrossRef] [PubMed]

30. Fortes, L.S.; Morgado, F.F.R.; Almeida, S.S.; Ferreira, M.E.C. Eating behavior and physical activity in adolescents. Rev. Nutr. 2013, 26, 529-537. [CrossRef]

31. Ilas, S. The Status of Nutritional Education in Preschool Education. Contents, Strategies and Perspectives for Improvement; Alexandru Ioan Cuza University: Iasi, Romania, 2016. 